\title{
DO DESFILE NA AVENIDA AO CAMAROTE: UM OLHAR DISCURSIVO SOBRE O CARNAVAL NOS CARTUNS DE ANGELI
}

\author{
Francis Lampoglia \\ Valdemir Miotello \\ Lucília Maria Sousa Romão
}

Resumo: Esse artigo estuda o funcionamento discursivo de dois cartuns de Angeli - originalmente publicados pelo jornal Folha de S. Paulo entre 2007 e 2009 - que tratam sobre o tema do carnaval. A forma como são trabalhados a memória discursiva, os sentidos e o posicionamento do sujeito são especialmente observados. Para tanto, trabalhamos com a teoria da Análise do Discurso de linha francesa fundada por Michel Pêcheux e Jean Dubois em 1969, e os estudos de Mikhail Bakbtin sobre dialogismo e carnavalização, conceitos esses que embasam nosso trabalho. A análise preliminar dos dados aponta para a emergência de um espaço de ruptura do sentido dominante sobre o que é considerado óbvio e natural quando se fala em carnaval no pais.

Palavras-chave: Carnaval. Análise do Discurso. Memória discursiva.

\section{INTRODUÇÃO: O SAMBA VAI PASSAR}

"vai passar nessa avenida um samba popular"- Chico Buarque

\footnotetext{
* Mestranda do Programa de Pós-graduação em Ciência, Tecnologia e Sociedade da Universidade Federal de São Carlos (PPGCTS/UFSCar), 2010. Bolsista FAPESP, processo n. 2010/03200-2. Email: francidusp@hotmail.com.

** Prof. Dr. do Departamento de Letras e do Programa de Pós-graduação em Linguística e do Programa de Pós-graduação em Ciência, Tecnologia e Sociedade da Universidade Federal de São Carlos (UFSCar). Doutor em Linguística, 2001. E-mail: miotello@terra.com.br.

*** Prof $^{a}$ Dr $^{a}$ do Curso de Graduação de Ciências da Informação e da Documentação e do Programa de Pós-Graduação em Psicologia da Faculdade de Filosofia, Ciências e Letras de Ribeirão Preto da Universidade de São Paulo (FFCLRP/USP). Professora colaboradora do Mestrado em Ciência, Tecnologia e Sociedade da Universidade Federal de São Carlos (UFSCar). CNPQ. Doutora em Psicologia, 2002. E-mail: luciliamsr@uol.com.br.
} 
O presente artigo estuda, sob a luz da teoria da Análise do Discurso de matriz francesa e da teoria bakhtiniana de dialogismo e carnavalização, dois trabalhos do cartunista Angeli que discursivizam o carnaval. Originalmente publicados no jornal Folha de S. Paulo entre 2007 e 2009, os cartuns selecionados como corpus de análise para este trabalho foram coletados a partir de seu tema em comum - o carnaval -, visando observar os sentidos inscritos nessa materialidade discursiva. $\mathrm{O}$ carnaval no Brasil recebe grande atenção da mídia, configurando-se, ao lado do futebol, como um dos maiores símbolos nacionais. Festa de caráter popular que embala diferentes classes sociais ao ritmo do frevo, do samba e das marchinhas de carnaval; contudo, essa socialização entre as classes, muitas vezes, não dura mais que o tempo dos desfiles de escolas de samba. Tomando o carnaval como objeto discursivo, iniciaremos nosso trabalho com uma breve discussão sobre os estudos de Mikhail Bakhtin e alguns conceitos trabalhados por Michel Pêcheux. Depois, observaremos as reflexões sobre o carnaval e a carnavalização, enfocando o olhar bakhtiniano sobre o tema. Em seguida, partiremos para a análise de nosso recorte, em que aplicaremos o olhar da teoria sobre o material coletado. E, por fim, concluiremos nossa trajetória sem a pretensão de exaurir o tema - com as considerações finais.

\title{
2 OLHARES DE PÊCHEUX E BAKHTIN SOBRE O DISCURSO: UM PERCURSO TEÓRICO
}

\begin{abstract}
"um dia página infeliz da nossa história, passagem desbotada da memória/ Dormia a nossa pátria mãe tão distraída sem perceber que era subtraída em tenebrosas transações" - Chico Buarque
\end{abstract}

A Análise do Discurso (AD) de matriz francesa, fundada por Michel Pêcheux e Jean Dubois em 1969, possui como objeto de estudo o discurso, que é concebido como efeito de sentido entre interlocutores (PÊCHEUX, 1997), o que coloca em foco a questão de que o sentido não está pronto, que as palavras transbordam pluralidade e desdobramentos a partir da posição dos interlocutores e das condições de produção. A AD de Pêcheux recupera alguns aspectos do dialogismo formulado por Bakhtin e incorpora-os em sua teoria. O dialogismo é um conceito amplo, que atravessa todos os estudos bakhtinianos. Essa 
noção abrange desde a constituição da linguagem - daí seu caráter constitutivo - até a relação entre os interlocutores.

O dialogismo é constitutivo da linguagem porque o discurso é construído por uma rede de "já-ditos" que fundamentam todo dizer. Toda fala resgata dizeres que já circularam outrora e, inseridos em novo contexto, tornam-se um outro dizer, apontando para novas possibilidades discursivas. Bakhtin (2002) reflete que o discurso "penetra neste meio dialogicamente perturbado e tenso de discursos de outrem, de julgamentos e de entonações" (p. 86), envolvendo-se com eles em "interações complexas, fundindo-se com uns, isolando-se de outros, cruzando com terceiros; e tudo isso pode formar substancialmente o discurso, penetrar em todos os seus estratos semânticos, tornar complexa a sua expressão, influenciar todo o seu aspecto estilístico" (BAKHTIN, 2002, p. 86). Essa rede de vozes que constrói a linguagem e o discurso é recuperada por Pêcheux e desdobrada nos conceitos de interdiscurso e memória discursiva. A noção de interdiscurso em $\mathrm{AD}$ refere-se ao conjunto de já ditos e esquecidos que determinam o que dizemos. Para Orlandi (2005, p. 33-34), "é preciso que o que foi dito por um sujeito específico, em um momento particular se apague na memória para que, passando para o 'anonimato', possa fazer sentido em 'minhas' palavras." Por vezes confundida com o interdiscurso, a memória é o dispositivo que embasa o dizer, dado que ela é da ordem do constitutivo da linguagem, enquanto o interdiscurso é limitado aos sujeitos que a ele têm acesso. Cazarin e Celada (2007, p. 4) entendem que a memória discursiva,

[...] embora tenha uma relação de intricamento com o interdiscurso, não tem com ele uma relação de equivalência. É a memória discursiva que possibilita compreender gestos de interpretação de diferentes posições de sujeito e aí joga o seu papel com relação a seu potencial espaço de coerência. Isto coloca em xeque uma relação de equivalência entre memória discursiva e interdiscurso.

É a memória discursiva que seleciona os sentidos a serem guardados ou descartados no arquivo discursivo. Para Pêcheux (1994), o 
arquivo pode ser entendido no sentido amplo de "campo de documentos pertinentes e disponíveis sobre uma questão" (PÊCHEUX, 1994, p. 57). Tais documentos não se referem aqui como materiais físicos, mas como conjunto de dizeres retomados do/no interdiscurso, constituindo-se no repertório, na base que sustenta a memória e possibilita a leitura. Também relacionado à noção de interdiscurso, o arquivo discursivo atua como repositório de sentidos regulado pela memória. Segundo Ferreira (2008, p. 22): “o mencionado "trabalho da memória" é um dos mecanismos que possibilita a constante reconfiguração do arquivo enquanto repositório dos sentidos, alternando um movimento necessário que vai oscilar entre presença e ausência, entre lembrança e esquecimento".

O dialogismo bakhtiniano é estudado também por Authier-Revuz ([1982] 2004; 1999), que reflete sobre essa noção e a desdobra no conceito de heterogeneidade discursiva, cujo mecanismo é incorporado aos estudos da $\mathrm{AD}$ pêcheutiana. A heterogeneidade discursiva indica a existência de vozes que ecoam, escorrem e deslizam em um discurso, podendo ser classificada em dois tipos, quais sejam, a mostrada e a constitutiva. A presença do outro pode ser detectada por meio de referências e citações literais e indiretas, aspas e exemplos, o que se configura no tipo de heterogeneidade denominada mostrada. A heterogeneidade mostrada sugere a influência dos estudos de Bakhtin (2006) sobre o discurso direto e indireto discutidos na obra Marxismo e filosofia da linguagem, assinada por Volochinov (mas que alguns estudiosos acreditam pertencer a Bakhtin). O outro tipo, que se relaciona ao dialogismo sob o aspecto constitutivo da linguagem, é a heterogeneidade constitutiva, que é da ordem da construção do dizer. Todo discurso é atravessado pelo discurso do outro, tendo em vista que, como afirma Authier-Revuz (1999, p. 10), "nenhuma palavra é virgem, mas, ao contrário, carregada, 'habitada' pelos discursos 'em que tenha vivido sua vida de palavra"”.

Outro aspecto do dialogismo bakhtiniano refere-se à forma como o locutor constrói seu discurso visando a resposta, a reação de seu interlocutor. Ou seja, o locutor forma uma imagem de seu interlocutor e modela seu discurso para obter determinada resposta. De acordo com Bakhtin, 
A quem se destina o enunciado, como o falante (ou o que escreve) percebe e representa para si os seus destinatários, qual é a força e a influência deles no enunciado - disto dependem tanto a composição quanto, particularmente, o estilo do enunciado (BAKHTIN, 2003, p. 301).

Esta característica do dialogismo possui semelhanças com os conceitos de antecipação e formação imaginária estudados por Pêcheux. O dispositivo denominado antecipação diz que, ao enunciar, o sujeito tem a possibilidade de colocar-se na posição de seu interlocutor, escutando as suas próprias palavras, prevendo e antecipando sentidos que sua enunciação poderá (ou poderia) produzir em seu interlocutor, imaginarizando também o objeto discursivo. Esse mecanismo, segundo Orlandi (2005, p. 39), "regula a argumentação, de tal forma que o sujeito dirá de um modo, ou de outro, segundo o efeito que pensa produzir em seu ouvinte". Já o mecanismo da formação imaginária é trabalhado como um conceito da $\mathrm{AD}$ em que o sujeito projeta a imagem de si e de seu interlocutor ao dirigir-se a ele, moldando, dessa forma, seu discurso. Para Orlandi (2005, p. 40-41), na relação discursiva "são as imagens que constituem as diferentes posições", isto é, não é o sujeito empírico que é posicionado mediante o exercício de suas funções, mas seu posicionamento é construído mediante as relações discursivas entre os sujeitos e a projeção imagética que o sujeito tem de si e dos outros.

Outros aspectos do dialogismo bakhtiniano (como a compreensão ativa e responsiva entre os interlocutores), assim como outras noções estudadas por Bakhtin - excetuando-se o conceito de carnavalização não serão explorados neste estudo, interessando-nos os pontos em que Bakhtin dialoga com a AD pêcheutiana. Com isso, nosso estudo tem por base o sujeito postulado por Pêcheux, que não é o empírico, o quantificável, o ser biológico, o que nos afasta da noção de indivíduo e falante como Bakhtin havia pensado. O sujeito aqui é uma posição discursiva, capturado pela ideologia e atravessado por palavras que não são suas, migrante em seu discurso. Para a $\mathrm{AD}$ francesa de Pêcheux, "importa o sujeito inserido em uma conjuntura social, tomado em um lugar social, histórica e ideologicamente marcado; um sujeito que não é homogêneo, e sim heterogêneo, constituído por um conjunto de diferentes vozes." (FERNANDES, 2005, p. 13) 
A ideologia, neste estudo, é o mecanismo de naturalização dos sentidos, isto é, o dispositivo que produz efeitos de evidência e a sensação de obviedade e transparência dos significados para o sujeito em uma dada posição. Conforme Orlandi (2004, p. 31), através da ideologia se naturaliza o que é produzido pela história: "há transposição de certas formas materiais em outras, isto é, há simulação [...] em que são construídas transparências [...] para serem interpretadas por determinações históricas que aparecem como evidências empíricas."

Fisgado pela ideologia, o sujeito imagina ser a fonte dos sentidos que produz e supõe ter o domínio de seu dizer, ilusões estas que configuram o mecanismo denominado esquecimentos pela $\mathrm{AD}$ (PÊCHEUX, 1997): o esquecimento de número um é pautado pela ilusão do sujeito de ser a origem do que diz, como se os sentidos brotassem nele, ignorando a preexistência dos mesmos. Já no esquecimento de número dois, o sujeito tem a ilusão de controlar os sentidos de suas palavras, imaginando a existência de uma correspondência direta entre o pensamento e o seu dizer, acreditando que esse processo só pode ser realizado dessa forma, "que o que dizemos só pode ser dito com aquelas palavras e não outras, que só pode ser assim." (ORLANDI, 2005, p. 35).

Ao enunciar, o sujeito tem a certeza de que escolhe e seleciona determinadas palavras, ao mesmo tempo em que silencia outras. Essa omissão de algumas formas do dizer configura o mecanismo da AD denominado silenciamento. A AD labora com a noção de que o silêncio atravessa as palavras e é portador de sentido, ou seja, o silêncio também é fonte de significação. O silenciamento pode ser compreendido em dois tipos, quais sejam, o silêncio fundador e a política do silêncio. $O$ primeiro tipo é "aquele que existe nas palavras, que significa o não-dito e que dá espaço de recuo significante, produzindo as condições para significar" (ORLANDI, 2007, p. 23-24), ou seja, o silêncio fundador é aquele que atravessa as palavras e que funda o dizer, dado que não se pode dizer tudo, pois a incompletude da linguagem ronda o discurso e o sujeito. Já a política do silêncio é subdividida em silêncio constitutivo e censura: o primeiro refere-se ao pressuposto de que ao escolher determinada palavra, são apagadas outras palavras e, consequentemente, outros sentidos são silenciados (ORLANDI, 2007; v. também ORLANDI, 2001). Já o silêncio local ou censura diz respeito ao que é 
proibido de se dizer em determinada conjuntura, ou seja, na censura ocorre a interdição do dizer, coibindo, dessa forma, a circulação de determinados significados.

Essa discussão nos conduz a refletir sobre os sentidos e seus limites, considerando-os movediços e postulando que os sentidos, que não são transparentes e nem fixados às palavras, são dependentes do contexto sócio-histórico-ideológico. Ou seja, todo portador de significado, seja uma palavra falada ou escrita, ou mesmo um gesto, não encerra dentro de si apenas um único e imutável sentido, unívoco e expressão do que o autor quis dizer, mas é capaz de instalar o outro, o novo, o plural de acordo com a contextualização socioideológica. Com isto, os sentidos não são nem totalmente livres, a ponto de ser qualquer um, nem completamente herméticos, incapazes de se deslocar e tornar-se outro. Dependendo das condições de produção, há a dominância de determinado sentido em detrimento de outros, mas isso não elimina outros sentidos possíveis.

[...] dadas certas condições, em que um sentido se coloca como dominante (legítimo, "literal"), delimita-se, na e pela interlocução, aquilo que é implícito e o que é explícito. E, como é a relação entre os dois que os delimita, podemos dizer que todo explícito determina implícitos e vice-versa. (ORLANDI, 1983, p. 158, apud INDURSKY, 1997, p. 26).

Pêcheux (1997) postula que os sentidos são constituídos nas relações que as palavras, expressões ou proposições mantêm entre si, inseridos em uma mesma formação discursiva (FD). Ou seja, os sentidos não estão prontos e acabados nas palavras, mas são construídos a partir do relacionamento com outras palavras e expressões dentro de uma FD. Por formação discursiva entende-se tudo o que pode e deve ser dito dentro de determinada conjuntura e posicionamento (PÊCHEUX, 1997). É a FD que produz certo grau de unidade entre os discursos, dado que é constituída por conjunto de sentidos sobre determinado grupo de significantes, atendendo a interesses específicos de um dado segmento social. Componente das formações ideológicas, a formação discursiva, embora apresente uma determinada coerência entre os 
discursos para atender a fins específicos, não é homogênea, mas sim atravessada por diferentes discursos, tornando-se, por vezes, palco de tensões e conflitos, devido às múltiplas posições ocupadas pelos sujeitos. Nas palavras de Fernandes (2005, p. 51), temos que

[...] uma formação discursiva nunca é homogênea, é sempre constituída por diferentes discursos. Um mesmo tema, ao ser colocado em evidência, é objeto de conflitos, de tensão, face as diferentes posições ocupadas por sujeitos que se opõem, se contestam.

Tais mecanismos discursivos, aqui discutidos, são fundamentais para o estudo dos cartuns selecionados como corpus de análise para este artigo. Por possuírem como tema o carnaval, explanaremos a seguir a importância e alguns significados desta festa na cultura popular, em especial, no contexto brasileiro.

\section{CARNAVAL E CARNAVALIZAÇÃO}

“Ai que vida boa, ô lerê, ai que vida boa, ô lará. O estandarte do sanatório geral vai passar" - Chico Buarque

O carnaval é uma festa popular de grande relevância na sociedade, capaz de abarcar indivíduos de diferentes classes, cores e crenças em um mesmo evento festivo. Não há consenso, porém, sobre suas origens: para alguns teóricos, o carnaval é oriundo do cristianismo, e para outros, do paganismo. Para Baroja (1979 apud SOIHET, 1998), o carnaval tem suas origens no cristianismo e contrapõe-se ao período da quaresma, momento tido como de recolhimento pela tradição católica. Embora de origem cristã, o carnaval possui elementos de festividades pagãs, em oposição aos valores cristãos da quaresma. O deslocamento da ordem física e normal das coisas, somado aos excessos na ordem social, caracterizavam o carnaval, funcionando como uma "catarse preparatória para justificar a entrada na quaresma” (SOIHET, 1998, p. 3). Já para Mikhail Bakhtin (1987), o carnaval tem suas raízes no paganismo e está 
inserido na cultura popular, o que, para este autor, elimina a distinção entre atores e espectadores, pois insere todos em um mesmo plano. Tal perspectiva pode ser elevada à ideia de plenitude social, em que as hierarquias cedem lugar à igualdade. Para Soihet (1998), Bakhtin conhecedor da dialética marxista - tece sua argumentação apoiado na inter-relação entre o material e o espiritual, o mundo das ideias e o corpo, com vistas à plenitude social e de suas formas de expressão.

Dialética e sensibilidade fazem emergir um mundo de alegria, de prazer sem culpa, despido de repressão e de hierarquias e onde todos são iguais, presente no período da festa, mais precisamente na maior delas - o carnaval. $O$ que estimula pensar-se na possibilidade de extrapolação daquele momento e de concretização no quotidiano de uma sociedade marcada pelo riso que jamais seria um instrumento da opressão. (SOIHET, 1998, p. 9)

O sagrado e o profano, o nascimento e a morte, a elevação e o rebaixamento são elementos presentes nessa festividade, momento em que os opostos convivem em um mesmo universo e de forma cômica, através do riso carnavalesco. Esse riso difere do riso individual proveniente de um fato cômico isolado, pois no carnavalesco todos riem, o riso é "geral" e patrimônio do povo. É também universal, pois atinge todas as coisas e pessoas, inclusive as que participam do carnaval (BAKHTIN, 1987, p. 10). E, por último, o riso carnavalesco é ambivalente, pois, ao mesmo tempo em que nega, afirma, é alegre e simultaneamente sarcástico, amortalha e ressuscita. Para Bakhtin, no carnaval, não há distinções sociais e/ou outras, o que ocorre são inversões da ordem das coisas e da vida; tais inversões, aliadas à abolição das fronteiras das hierarquias sociais, marcam o efeito denominado por Bakhtin carnavalização. Rituais sagrados são parodiados, os bufões são coroados reis, até mesmo a linguagem é afetada por essa eliminação provisória da ordem do mundo.

[...] todas as formas e símbolos da linguagem carnavalesca estão impregnados do lirismo da alternância e da renovação, da consciência da alegre relatividade das verdades e autoridades no 
poder. Ela caracteriza-se, principalmente, pela lógica original das coisas "ao avesso", "ao contrário", das permutações constantes do alto e do baixo ("a roda"), da face e do traseiro, e pelas diversas formas de paródias, travestis, degradações, profanações coroamentos e destronamentos bufões (BAKHTIN, 1987, p. 9-10).

A festa oficial - com privilégios, regras, hierarquias, tabus e etiquetas - é parodiada pelo carnaval, de forma a utilizar esses elementos de ostentação e subvertê-los, rebaixando-os com a licença do riso. No Brasil, Queiroz (1992) e Matta (1981) destacam que a festa carnavalesca é um momento de catarse popular que é permitido e controlado pela classe dominante, a fim de manter sua hegemonia. Por esse ponto de vista, o carnaval seria, então, uma liberdade popular restrita a limites preestabelecidos e controlados pela classe dominante. Contudo, segundo Soihet (1998), muitos historiadores combatem tal acepção, pois existem muitas estratégias de resistência dos populares no campo cultural em relação às proposições das classes dominantes. Bakhtin, entretanto, não aposta nessa ideia de liberdade restrita a anseios da elite. Ao contrário, o autor russo propõe o carnaval como um momento de igualdade entre os indivíduos, em que as diferenças hierárquicas são abolidas em função da força regeneradora criadora do riso carnavalesco.

No caso brasileiro, o carnaval proporciona esse relacionamento entre classes com relativa igualdade, porém em um período de tempo limitado ao desfile na passarela do samba. Após desfilar na avenida, na maioria das vezes, a elite dirige-se ao camarote, à bancada restrita à classe alta, enquanto os pobres tomam rumos ignorados pela grande mídia, apenas fazendo volume nas alas e arquibancadas. Com isto, o conceito de eliminação provisória das barreiras hierárquicas apontadas por Bakhtin no contexto rabelaisiano também é válida no contexto brasileiro, já que é possível observar tal fenômeno em situações como nos desfiles das escolas de samba. Mas, como o próprio Bakhtin indica, tal eliminação de classes é provisória, sendo logo após o evento, restaurada. 


\title{
4 CONSIDERAÇÕES SOBRE O CARTUM E ANÁLISE DISCURSIVA DAS POSIÇÕES DE ELITE E POVO NA AVENIDA
}

\author{
"Seus filhos erravam cegos pelo continente, levavam pedras feito \\ penitentes Erguendo estranhas catedrais." - Chico Buarque
}

O material selecionado para o corpus de análise para esse artigo é constituído por dois cartuns de Angeli, publicados no jornal Folha de S. Paulo, que tratam do tema carnaval; tal escolha foi efetuada dado o apelo que essa festa popular possui na vida dos brasileiros e nos discursos que circulam socialmente sobre o carnaval como maior festa do país. Mas antes de iniciarmos a análise dos cartuns, cabe aqui considerar que cartuns e charges utilizam-se da estratégia do riso e da comicidade para criticar um determinado assunto. Há, entretanto, uma diferença entre os dois, pois enquanto o cartum critica uma realidade genérica e "chega ao riso através da crítica mordaz, irônica, satírica e principalmente humorística do comportamento humano, de suas fraquezas e de seus hábitos e costumes" (ROMUALDO, 2000, p. 20), a charge é um texto visual humorístico que critica um evento específico, "uma personagem, fato ou acontecimento político específico. Por focalizar uma realidade específica, ela se prende mais ao momento, tendo, portanto, uma limitação temporal" (ROMUALDO, 2000, p. 21-22). Neste trabalho, utilizamos a denominação cartum devido ao enfoque dado ao tema carnaval que consideramos não vinculado a personagens ou a tempo específicos, mas faz referência ao comportamento observado com certa regularidade nestes períodos festivos.

Diante dessa diferenciação entre charge e cartum, partimos para a análise. O primeiro cartum a ser analisado foi publicado em 2009 e discursiviza a separação das classes sociais em meio à folia - fenômeno que se afasta do efeito de carnavalização - enquanto que o segundo cartum aproxima-se do postulado de Bakhtin ao demarcar, por meio do dizer de uma das personagens, o reerguimento das fronteiras que separam ricos e pobres com o fim da festividade, indicando que, durante a comemoração, tais fronteiras haviam sido eliminadas ou que elas ficam 
mais móveis, menos cristalizadas, o que promove a sustentação provisória de uma igualdade pela via do samba e do desfile da escola.

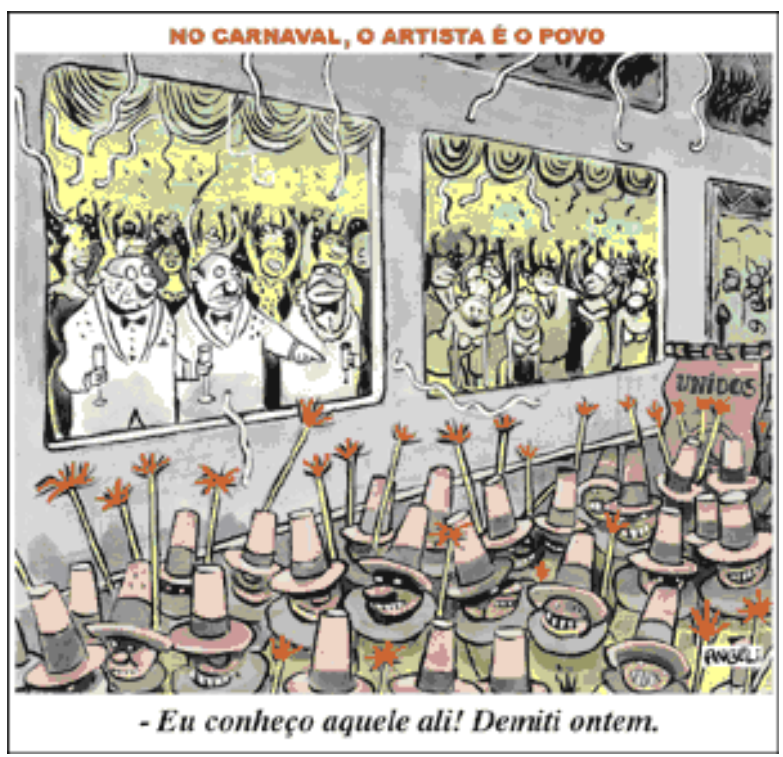

Figura 1 - Cartum de Angeli originalmente publicado pela Folha de S. Paulo em 23/02/2009.

Fonte:<<http://pelaluzdosmeusolhos.blogspot.com/2009/02/quando-umasimples-charge-sugere-um.html>. Acesso em: 25 mar. 2010.

Pela memória discursiva, inferimos que o cartum acima, originalmente publicado no jornal Folha de S. Paulo em 23 de fevereiro de 2009, discursiviza o cenário típico do desfile de grandes escolas de samba, algo que ocorre em cidades como Rio de Janeiro e São Paulo. A festa é dividida entre os que desfilam na avenida do samba e aqueles que ficam no camarote, espaço este que geralmente é repleto de personagens da elite - artistas, empresários, convidados Vips - com exceção dos trabalhadores contratados para servir a essa classe abastada. Estar no camarote é, assim, marca de um distintivo social, visto que o acesso é garantido pela condição de convidados ou pagantes endinheirados que desfrutam das mordomias de uma vista privilegiada do alto da avenida, 
de um serviço diferenciado de comes e bebes, de um entretenimento organizado com rigor (muitos camarotes oferecem massagistas para os pés, colchões de água para o relaxamento, entre outros serviços).

Neste cartum é retratada pictoricamente essa divisão de classes, marcada por sujeitos de smoking num andar superior e por foliões que trajam a mesma fantasia e dançam na avenida, indicando pertencerem a um mesmo bloco (carnavalesco ou de classe). Notamos que os primeiros, de gravata borboleta que indicia um vestuário seleto e caro, observam, assistem ao desfile numa posição de espectador, posição essa que é confirmada pela acepção da palavra "artista" designada ao povo, o que inscreve discursivamente os primeiros na posição de plateia. Tal posicionamento confronta-se com a ideia de carnaval proposta por Bakhtin, que diz que

[...] o carnaval ignora toda distinção entre atores e espectadores. Também ignora o palco, mesmo na sua forma embrionária. Pois o palco teria destruído o carnaval [...]. Os espectadores não assistem ao carnaval, eles o vivem, uma vez que o carnaval pela sua própria natureza existe para todo o povo." (BAKHTIN, 1987, p. 6, grifos do autor).

Com isto, o carnaval colocado em discurso pelo sujeito cartunista assemelha-se a uma festa oficial, com distinções hierárquicas e classistas, em que os lugares sociais estão mais enrijecidos e cristalizados pelas posições de classe e de poder do que o conceito de carnavalização de Bakhtin. Ou seja, essa divisão entre camarote e passarela, ricos e pobres, descaracteriza a própria essência do carnaval, tornando-se uma paráfrase de uma festa oficial. Na frase: "No carnaval, o artista é o povo", a palavra "artista" recupera, pela memória discursiva e pelo contexto, sentidos de pessoa famosa, um astro das grandes mídias que é observado e para o qual os olhares são direcionados. Com isto, percebe-se que o "sentido se forma na história através do trabalho da memória" (MALDIDIER, 2003, p. 96), ou seja, os sentidos são dependentes da historicidade e da memória discursiva, que resgata sentidos anteriormente formulados. No jogo das projeções imaginárias, ser artista aqui faz falar o efeito de garantia e certeza de ser a diversão do outro, ou 
seja, o povo fantasiado na avenida assegura o entretenimento dos que ocupam o camarote; o que inverte o sentido de simetria entre os interlocutores.

Como analistas do discurso, estranhamos a marca linguística "povo", visto que, no contexto social e histórico aqui desenhado, ela inscreve o efeito, não de "conjunto das pessoas que constituem o corpo de uma nação, que se submetem às mesmas leis" (FERREIRA, 1986, p. 1375), mas de "plebe" (1986, p. 1375), de sujeitos pertencentes a uma classe pouco (ou nada) favorecida economicamente, cuja possibilidade de ser artista materializa-se apenas no carnaval. Essa restrição faz movimentar, pelo silêncio de outros modos de dizer, o sentido de que apenas no carnaval o povo é colocado na posição de artista sendo respeitado pela sua inventividade e criação.

Observamos, ainda, que tais efeitos de separação e distinção retornam no enunciado "Eu conheço aquele ali!"; no trecho "aquele ali" funciona discursivamente outro modo de distanciamento entre quem fala e o sujeito de quem se fala, indicando um sentido de aproximação que se faz notar pela exclusão. Aquele que se conhece, agora como artista, foi demitido ontem, o que instala uma estranha intimidade entre os dois personagens que se encontram na mesma festa. Conhecer alguém nos põe a criar, para nós, a expectativa de uma proximidade e de um conhecimento entre os dois pela via de algum ponto de contato; no entanto, o conhecer aqui está posto pela via do que se reconhece como mão-de-obra eliminada, desprezada e descartada. Ou seja, ao invés do vínculo, a ruptura, até porque o sujeito apontado é só mais um na multidão, sem nome, sem rosto e sem identidade (pois não se diz o nome, ou melhor, seu nome é apenas "aquele ali", um demonstrativo e uma indicação de lugar), remontando ao silêncio que aqui significa.

$\mathrm{Na}$ continuação, o verbo é flexionado no passado, "Demiti ontem". Os sentidos de poder marcam a posição do sujeito que fala de uma instância superior e decisória, o que imediatamente coloca o sujeito de quem se fala em uma posição inferior à sua, passível de ser descartado do quadro de funcionários do primeiro. Em vista disso, observa-se que o sentido é construído a partir das condições sócio-históricas e ideológicas de sua produção. 
[...] o sentido de uma palavra, de uma expressão, de uma proposição, etc., não existe "em si mesmo" (isto é, em sua relação transparente com a literalidade do significante), mas, ao contrário, é determinado pelas posições ideológicas que estão em jogo no processo sócio-histórico no qual as palavras, expressões e proposições são produzidas (isto é, reproduzidas). Poderíamos resumir essa tese dizendo: as palavras, expressões, proposições, etc., mudam de sentido segundo as posiçoes sustentadas por aqueles que as empregam, o que quer dizer que elas adquirem seu sentido em referência a essas posições, isto é, em referência às formações ideológicas [...] nas quais essas posições se inscrevem (PÊCHEUX, 1997, p. 160, grifos do autor).

Observa-se também a heterogeneidade de vozes que atravessam o cartum por meio do discurso do carnaval sob o enfoque do popular e da elite, além do discurso das desigualdades sociais materializadas na relação entre patrão e empregado. De uma forma não explícita, tais discursos encontram-se emaranhados, diluídos nos dizeres verbais e não verbais do cartum, remontando à heterogeneidade constitutiva que compõe tal materialidade discursiva. Percebe-se também que há uma demarcação da fala do outro no quadro, separando a fala do narrador e a fala do personagem. O travessão, marca da heterogeneidade discursiva mostrada, postulada por Authier-Revuz (1999), marca o distanciamento entre as falas do narrador e da personagem, apontando a presença de mais de uma voz no trecho em estudo.

Notamos, por fim, que no canto do cartum há um estandarte com o dizer "unidos", que remete, pela memória discursiva, aos nomes de escolas de samba (por exemplo, "Unidos de Vila Maria", "Unidos do Peruche", entre outros); mas que, pelos sentidos apontados até aqui, permite-nos fazer uma outra leitura, qual seja, o risível sentido de união entre os semelhantes, de horizontalidade, de que todos que estão naquele nível pertencem a um mesmo bloco, a uma mesma classe ou nação, dadas as posições em que os sujeitos se encontram e a similaridade de suas vestimentas e rostos. A ironia joga justamente aí onde o naturalizado é desconstruído. Sendo o carnaval uma festa popular de grande proporção, poderia parecer evidente a garantia de uma união entre todos tal como apontava Bakhtin, união essa não apenas dos 
integrantes de uma escola ou ala, mas de todos os brasileiros a brincarem em iguais posições durante os quatro dias de folia. No entanto, o risível está justamente no inverso ao de "união", pois persiste a separação entre ricos e pobres; estes últimos são assistidos e ridicularizados pelos primeiros, ironicamente posicionados como "artistas". Diante desse furo da completude de simetria imaginariamente inscrita no carnaval, é possível identificar o cruzamento de duas vozes, uma que afirma a posição artística do povo e outra que a nega, confirmando que "o texto irônico é sempre polifônico" (BRAIT, 1996), entendendo-se por polifonia o conjunto de vozes polêmicas e equipolentes num discurso. Tais vozes presentes neste texto irônico confirmam também o caráter dialógico constitutivo do texto.

O mesmo teor irônico pode ser observado no cartum da página seguinte, onde o funcionamento discursivo nos aponta duas temporalidades, a primeira a da festa carnavalesca, marcadamente uma festa que seria "democrática"; a segunda a do final da festa, quando o "agora" restabelece os lugares devidos à patroa e empregada. Aqui a democracia opõe-se à separação de classes sociais; contrariamente ao primeiro cartum analisado, esse coloca ricos e pobres num mesmo plano - os sujeitos estão posicionados em um mesmo nível e suas vestimentas são semelhantes, ou seja, tanto a patroa quanto a empregada usam a mesma fantasia - marcando que até aquele momento as barreiras entre as classes sociais haviam sido rompidas e as classes misturaram-se no mesmo ritmo festivo do desfile. Neste cartum, o postulado bakhtiniano é reafirmado, na medida em que se verifica a eliminação provisória das hierarquias durante o festejo, garantindo que as duas mulheres ocupem posições aparentemente iguais. Esse efeito pode ser observado através do trecho em que é anunciado não o começo da festividade, mas no fim, quando a folia acaba. 


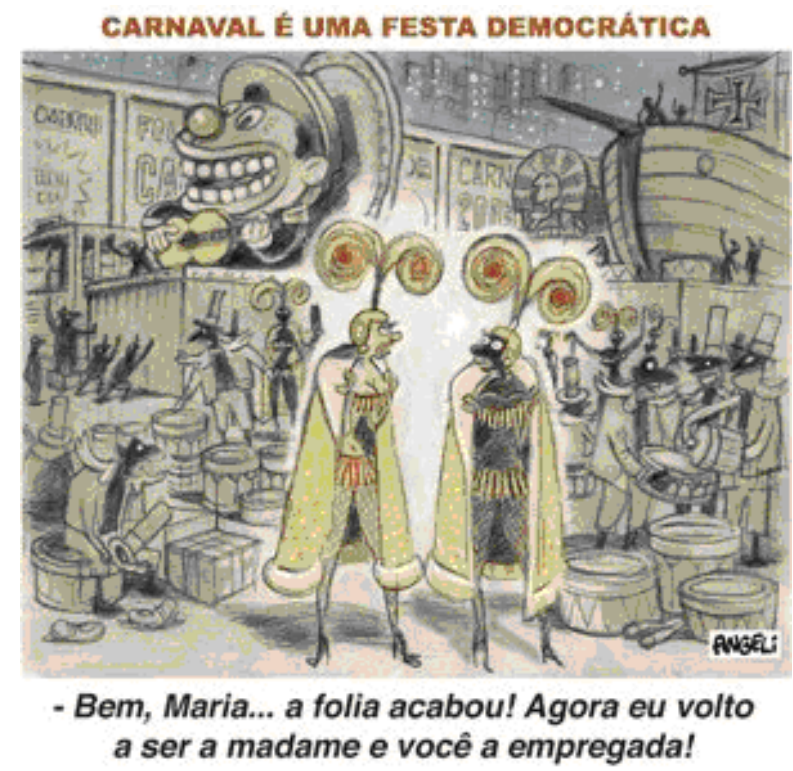

Figura 2 - Cartum de Angeli originalmente publicado pela Folha de S. Paulo. Fonte: Disponibilizado eletronicamente em 21/02/2007 em: $<<$ http://esquerdafestiva.blogspot.com/2007_02_01_archive.html $>>$. Acesso em: 25 de mar. 2010.

No dizer "Bem, Maria... a folia acabou! Agora eu volto a ser madame e você a empregada!", notamos que o sujeito reposiciona-se discursivamente como madame e posiciona seu interlocutor como empregada, o que exemplifica o efeito da formação imaginária em $\mathrm{AD}$ e nos convoca a pensar "quem sou para que lhe fale assim?, quem é você para que eu lhe fale assim" (PÊCHEUX, 1990, p. 83). Buscando responder essas questões, inferimos que ao dizer "a folia acabou", o sujeito restabelece o lugar de serviçal ao outro, definindo quem manda (ele mesmo) e quem deve obedecer (o outro), endereçando ao outro o lugar de subalterno. É como se a brincadeira tivesse terminado, e agora não é mais a vestimenta ou outro indício que revela a posição do sujeitoempregada, mas a fala do sujeito-madame que o coloca nessa posição. Além disso, as palavras "madame" e "empregada" inscrevem sentidos de hierarquia, de poder, sentidos esses que haviam se rompido provisoriamente durante o carnaval. A palavra "madame" sugere ainda 
efeitos de mordomia, luxo e ócio, enquanto que a marca "empregada", nesse contexto, produz sentidos de subserviência, trabalho braçal e submissão. Nota-se que quem anuncia o fim da folia é o sujeito-madame, produzindo um efeito de sentido de quem dita as regras; quem estabelece quando a festa começa ou acaba é o sujeito-madame. A marca "volto" na frase indica um sentido de retorno, de continuidade de como era antes do carnaval, o que indica o resgate de algo que foi interrompido, marcando a presença de um interdiscurso compartilhado pelos interlocutores. A naturalidade com que se concebe o retorno às relações de poder e à desigualdade social no fim do carnaval é devida à ação da ideologia, que faz com que a divisão social em classes seja concebida como natural e evidente na sociedade contemporânea.

Neste cartum, num olhar mais atento, não se discute apenas a relação entre classes sociais no contexto do carnaval, mas o atravessamento pela discussão do relacionamento entre negros e brancos. Observa-se que, ao falar, o sujeito-madame mobiliza um conjunto de dizeres que compõem a formação discursiva da mulher rica, da elite, branca, em contraposição à FD da mulher empregada, negra, que precisa do trabalho para (sobre)viver. Nota-se que o sujeito-madame é a única não negra neste cartum, o que remonta à característica da aristocracia - ou seja, do poder de poucos que controlam os demais - o que confronta-se com o trecho "festa democrática" postada na parte superior do cartum.

Esta relação entre negros e brancos, poder e submissão é reforçada pelo plano de fundo do cartum, em que aparecem sujeitos negros nos bastidores, com seus instrumentos e no canto superior direito uma caravela ostentando a Cruz de Malta, símbolo dos portugueses colonizadores. Tal símbolo remete à memória discursiva da colonização e da escravidão, resgatando uma parte da história brasileira cujos efeitos persistem até hoje. A cor da pele, que antes separava senhores e escravos, hoje distingue patrões e empregados.

A heterogeneidade constitutiva que constrói essa materialidade é composta pelo discurso da colonização, da discriminação racial e econômica, além do discurso do carnaval como festa dita "democrática", pois reúne foliões de diferentes classes sociais em um dado espaçotempo. Já a heterogeneidade mostrada aparece neste cartum, assim como no primeiro recorte analisado, marcada por um travessão, indicando ser 
uma voz outra que não a do narrador ou da empregada, mas provinda da patroa, indicando a presença de várias vozes no cartum analisado.

\section{CONSIDERAÇÕES FINAIS}

“até o dia clarear" - Chico Buarque

Neste artigo foram trabalhados conceitos teóricos da Análise do Discurso de linha francesa e dos estudos bakhtinianos, a fim de compreender o funcionamento do discurso nos cartuns de Angeli. No percurso deste estudo, discutimos os sentidos de carnaval e carnavalização postulados por Bakhtin e observamos o modo como essa noção atravessa o material selecionado para a análise. Também foi notado, através dos mecanismos da $\mathrm{AD}$, como os sentidos não são imanentes às palavras e como a memória discursiva atravessa o dizer.

Nos dois cartuns analisados é flagrado o momento da quebra da aliança momentânea entre ricos e pobres, pois enquanto o segundo cartum demonstra que a planificação entre hierarquias chega ao fim junto com o carnaval, o primeiro aponta, do alto do camarote, que essa aliança nunca existiu. Com isto, o carnaval estudado por Bakhtin, em que havia a abolição das fronteiras sociais entre sujeitos, não encontra uma ressonância muito clara no Brasil, país marcado pela desigualdade social. Muitas vezes, a elite procura essa divisão, esse isolamento dos demais indivíduos ou num camarote ou até mesmo na passarela do samba, em que os ricos e famosos aparecem frequentemente ou do alto de um carro alegórico ou na frente da bateria, lugares que os destacam e os isolam da multidão. E se essa convivência entre diferentes classes se concretiza, não termina na quarta-feira de cinzas, mas no final da avenida. 


\section{REFERÊNCIAS}

AUTHIER-REVUZ, J. (1982). Heterogeneidade mostrada e heterogeneidade constitutiva: elementos para uma abordagem do outro no discurso. In:

Entre a transparência e a opacidade: um estudo enunciativo do sentido. Porto Alegre: EDIPUCRS, 2004.

. Dialogismo e divulgação científica. Rua: revista do Núcleo de

Desenvolvimento da Criatividade, Campinas, n. 5, mar. 1999.

BAKHTIN, M. A cultura popular na Idade Média e no Renascimento: o contexto de François Rabelais. São Paulo: HUCITEC, 1987.

Questões de literatura e de estética: a teoria do romance. São Paulo: HUCITEC, 2002.

. Estética da criação verbal. São Paulo: Martins Fontes, 2003.

BAKHTIN, M.(VOLOSCHINOV). Marxismo e filosofia da linguagem. São Paulo: HUCITEC, 2006.

BAROJA, J. C. Le carnaval. Paris: Gallimard, 1979.

BRAIT, B. Ironia em perspectiva polifônica. Campinas: Editora da Unicamp, 1996.

CAZARIN, E. A.; CELADA, M. T. Interdiscurso, pré-construído, discurso transverso e memória. In: SEMINÁRIO DE ESTUDOS EM ANÁLISE DO DISCURSO, 3., 2007, Porto Alegre. Anais... Porto Alegre, UFRGS, 2007. p. 1 5.

FERNANDES, C. A. Análise do Discurso: reflexões introdutórias. Goiânia: Trilhas Urbanas, 2005.

FERREIRA, A. B. H. Novo dicionário da língua portuguesa. 2. ed. Rio de Janeiro: Nova Fronteira, 1986.

FERREIRA, M. C. L. A ciranda dos sentidos. In: GASPAR, N. R.; ROMÃO, L. M. S. (Orgs.). Discurso e texto: multiplicidade de sentidos na ciência da informação. São Carlos: Edufscar, 2008.

INDURSKY, F. A fala dos quartéis e as outras vozes. Campinas: Editora da Unicamp, 1997.

MALDIDIER, D. A inquietação do discurso: (re)ler Michel Pêcheux hoje. Campinas: Pontes, 2003. 
MATTA, R. Carnavais, malandros e heróis: para uma sociologia do dilema brasileiro. 3. ed. Rio de Janeiro: Zahar, 1981.

ORLANDI, E. P. A linguagem e seu funcionamento: as formas do discurso. São Paulo: Brasiliense, 1983.

Discurso e texto: Formulação e circulação dos sentidos. Campinas: Pontes, 2001.

. Interpretação: autoria, leitura e efeitos do trabalho simbólico.

Campinas: Pontes, 2004. 2005.

Análise de discurso: princípios e procedimentos. Campinas: Pontes,

As formas do silêncio: no movimento dos sentidos. Campinas:

Unicamp, 2007.

PÊCHEUX, M. Análise automática do discurso (AAD-69). In: GADET, F.;

HAK, T. (Orgs.). Por uma análise automática do discurso: uma introdução à obra de Michel Pêcheux. Campinas: Editora da Unicamp, 1990. p. 61-161.

. Ler o arquivo hoje. In: ORLANDI, E. P. (Org.). Gestos de leitura: da história no discurso. Campinas: Editora da Unicamp, 1994. p. 55-66.

Semântica e discurso: uma crítica à afirmação do óbvio. Campinas:

Editora da Unicamp, 1997.

QUEIROZ, M. I. P. Carnaval brasileiro: o vivido e o mito. São Paulo:

Brasiliense, 1992.

ROMUALDO, E. C. Charge jornalística: intertextualidade e polifonia: um estudo de charges da Folha de S. Paulo. Maringá: Eduem, 2000.

SOIHET, R. Reflexões sobre o carnaval na historiografia: algumas abordagens. Academia do samba. Publicado em 1998. Disponível em: <http://www.academiadosamba.com.br/monografias/raquelsoihet.pdf.>. Acesso em: 24 mar. 2010.

Recebido em 03/04/10. Aprovado em 26/01/11. 
Title: From the Street Parade to the Private Box: A Discursive Gaze over the Carnival in the Comics by Angeli

Authors: Francis Lampoglia, V aldemir Miotello, Lucilia Maria Sousa Romão

Abstract: This paper examines the discursive workings of two cartoons by Angeli - originally published by Folha de São Paulo from 2007 through 2009 - that have Brazilian carnival for its theme. Especial attention is given to how the discursive memory, the senses and the subject's position are worked. Such analysis is based on the French Discourse Analysis by Michel Pêcheux and Jean Dubois in 1969 and on Mikhail Bakhtin's studies on dialogism and carnivalization, concepts that are the basis of this work. The preliminary analysis of the data suggests the emergence of a space for rupture of the dominant sense about what is considered obvious and natural in Brazil when the theme is carnival.

Keywords: Carnival. Discourse Analysis. Discursive memory.

Titulo: Del desfile en la avenida al palco: una mirada discursiva sobre el carnaval en las viñetas de Angeli

Autores: Francis Lampoglia, Valdemir Miotello, Lucilia Maria Sousa Romão

Resumen: Este articulo estudia el funcionamiento discursivo de dos viñetas de Angeli - originalmente publicadas por el periódico Folha de S. Paulo entre 2007 y 2009 - que tratan sobre el tema del carnaval. La forma como son trabajados la memoria discursiva, los sentidos y el posicionamiento del sujeto son especialmente observados. Para tanto, trabajamos con la teoría del Análisis del Discurso de linea francesa fundada por Michel Pêcheux y Jean Dubois en 1969, y los estudios de Mikhail Bakbtin sobre dialogismo y carnavalización, conceptos estos que permean nuestro trabajo. El análisis preliminar de los datos apunta para la emergencia de un espacio de ruptura del sentido dominante sobre lo que es considerado obvio y natural cuando se habla en carnaval en el país.

Palabras-clave: Carnaval. Análisis del Discurso. Memoria discursiva.

LAMPOGLIA; MIOTELLO; ROMÃO - Do desfile na avenida ao camarote... 